\title{
Application of the 3-PG Model for Gross Primary Productivity Estimation in Deciduous Broadleaf Forests: A Study Area in Japan
}

\section{Supannika Potithep $^{1, *}$ and Yoshifumi Yasuoka ${ }^{2}$}

1 Department of Geography, Faculty of Social Sciences, Kasetsart University, 50 Ngamwongwan Road, Ladyao, Jatujak 10900, Thailand

2 National Institute for Environmental Studies, 16-2 Onogawa, Tsukuba 305-8506, Japan;

E-Mail: yyasuoka@nies.go.jp

* Author to whom correspondence should be addressed; E-Mail: fsocskpo@ku.ac.th;

Tel.: +66-2-561-3480; Fax: +66-2-561-2738.

Received: 21 February 2011; in revised form: 28 March 2011 / Accepted: 7 April 2011 /

Published: 6 May 2011

\begin{abstract}
The physiological principles predicting growth (3-PG) model is generally used to estimate gross primary productivity (GPP) in forest plantations. All existing parameter values in the 3-PG model for GPP estimation have been set as the standard values for eucalyptus and pine plantations. We propose that the 3-PG model can be applied to deciduous broadleaf forests dominated by Betula platyphylla via appropriate parameterization of their structure and functions. The allometric relationships between stem biomass and stem diameter, and between foliage biomass and stem biomass, were determined for the biomass partitioning ratio. Additionally, a temperature modifier was considered appropriate because it affected canopy quantum efficiency. After parameterization, the model showed a good correlation between the estimated results and the data from experimental plots in central and northern Japan. At both sites, GPP peaked around August and was 0 during the winter, when the canopy is bare of leaves. Furthermore, a sensitivity analysis was conducted to determine the most influential parameter relative to the output. GPP was sensitive to changes in canopy quantum efficiency and optimum temperature. Among the meteorological data used, solar radiation and temperature had great impacts on GPP, therefore, these parameters should be carefully considered to produce accurate results.
\end{abstract}


Keywords: the 3-PG model; GPP; deciduous broadleaf forest; parameterization; sensitivity analysis

\section{Introduction}

Process-based models, which were created in response to studies examining changes in environmental factors or management interventions [1,2], have the potential to reflect the nonlinear relationships between physiological processes and environmental factors. In forests, environmental factors affect the canopy structure, canopy density, biomass partitioning, and physiological processes. Intensive studies of the effects of environmental factors improve researchers' understanding of processes influencing forest growth [3].

Among process-based models, the physiological principles predicting growth (3-PG) model is often used to estimate forest properties in fast-growing forests and forest plantations [3-7]. The 3-PG model has been used to bridge the gap between conventional empirical, mensuration-based growth and yield models, and process-based carbon balance models [8]. The 3-PG model is primarily used for forest plantations or even-aged, relatively homogeneous forests, but this type of model can also be applied to various environments and species. However, parameterization is needed for individual species [9]. Eucalyptus globulus and E. grandis were initially parameterized by Sands and Landsberg [10] and Almeida et al. [11]. For other species, parameter values were adjusted to fit the output based on in situ measurements. Dye [7] and Dye et al. [12] used the 3-PG model to predict the growth and water use of Pinus patula and eucalyptus plantations. This model has been applied to analyses of forest productivity of various species in countries such as Australia, Brazil, Canada, New Zealand, South Africa, and the U.S. [3,4,13-16]. However, parameterizations are still lacking, especially for natural forests which can act as carbon sinks. To develop parameter values for natural forests, in situ measurements are required.

Forest ecosystems in middle and high latitudes of the northern hemisphere have large effects on the carbon cycle, because leaf phenological processes of forests in these regions, such as deciduous broadleaf forests, correspond to carbon sequestration. In this paper we attempted parameterization of the 3-PG model for deciduous broadleaf forests in Japan. We focused on parameters related to biomass production because biomass related to outputs as GPP provides valuable information that will aid in understanding the carbon status of the biosphere. The objective of this study was to assign standard parameter values for deciduous broadleaf forests in the 3-PG model that the original model and previous studies have not calibrated. Our results should make the 3-PG model more applicable to additional species. Moreover, sensitivity analyses were conducted to investigate the parameters with the most influence on output. Parameters identified as sensitive could then be carefully parameterized to calculate output with higher accuracy. 


\section{The 3-PG Model}

\subsection{Overview}

Landsberg and Waring [8] initiated the 3-PG model as a simple process-based model, on the stand level, for forest growth. The model is composed of five sub-models: assimilation of carbohydrates; biomass partitioning to foliage, stem, and roots; determination of stem number; soil water balance; and the conversion of biomass into variables of interest to forest managers.

\subsection{Data Inputs}

The main input parameters required are site factors and species-specific data of the species of interest (Table 1). The site factors include latitude, maximum available soil water $\left(A S W_{x}: \mathrm{mm}\right)$, soil texture (sandy, sandy loam, clay, or clay loam), and fertility rating $(F R)$. Species-specific parameter values are adjusted for each species. If the parameter values for a species do not exist, parameterization of the new site-specific parameter is necessary. Another input is meteorological variables, including mean air temperature $\left(T_{a}:{ }^{\circ} \mathrm{C}\right)$, mean solar radiation $\left(S R: \mathrm{MJ} \mathrm{m}^{-2}\right.$ day $\left.^{-1}\right)$, total precipitation $(R: \mathrm{mm})$, frost days ( $d_{F}$ : days per month), and vapor pressure deficit ( $V P D$ : mbar). If $V P D$ is not available, it can be calculated from the maximum and minimum temperatures $\left(T_{x}\right.$ and $T_{n}$ : $\left.{ }^{\circ} \mathrm{C}\right)$ as half the difference between the saturated vapor pressure at $T_{x}$ and $T_{n}$. The meteorological inputs can be actual monthly data or long-term monthly averages.

Table 1. List of all parameters of species specific with descriptions, symbols and unit.

\begin{tabular}{|c|c|c|}
\hline Description of parameter & Symbol & Units \\
\hline \multicolumn{3}{|l|}{ Biomass partitioning and turnover } \\
\hline \multicolumn{3}{|l|}{ Allometric relationships \& partitioning } \\
\hline Ratio of foliage:stem partitioning at $B=2 \mathrm{~cm}$ & $p_{2}$ & - \\
\hline Ratio of foliage:stem partitioning at $B=20 \mathrm{~cm}$ & $p_{20}$ & - \\
\hline Constant in stem mass $v$ diam. relationship & $a_{S}$ & - \\
\hline Power in stem mass $v$ diam. relationship & $n_{S}$ & - \\
\hline Maximum fraction of NPP to roots & $R x$ & - \\
\hline Minimum fraction of NPP to roots & $R n$ & - \\
\hline \multicolumn{3}{|l|}{ Litterfall \& root turnover } \\
\hline Litterfall rate at $t=0$ & $F 0$ & month $^{-1}$ \\
\hline Litterfall rate for mature stands & $F 1$ & month $^{-1}$ \\
\hline Age at which litterfall rate has median value & $t_{F}$ & month \\
\hline Average monthly root turnover rate & $R$ & month $^{-1}$ \\
\hline \multicolumn{3}{|l|}{ Growth modifiers } \\
\hline \multicolumn{3}{|l|}{ Temperature modifier } \\
\hline Minimum temperature for growth & $T_{n}$ & ${ }^{\circ} \mathrm{C}$ \\
\hline Optimum temperature for growth & $T_{o p t}$ & ${ }^{\circ} \mathrm{C}$ \\
\hline Maximum temperature for growth & $T_{x}$ & ${ }^{\circ} \mathrm{C}$ \\
\hline \multicolumn{3}{|l|}{ Frost modifier } \\
\hline Number of days production lost for each frost day & $k F$ & days \\
\hline
\end{tabular}


Table 1. Cont.

\section{Description of parameter \\ Fertility modifiers \\ Value of $m$ when $F R=0$ \\ Value of $f_{N}$ when $F R=0$ \\ Power of $(1-F R)$ in $f_{N}$ \\ VPD modifier}

Defines stomatal response to VPD

\section{Soil water modifier}

Moisture ratio deficit which gives $f_{\theta}=0.5$

Power of moisture ratio deficit in $f_{\theta}$

\section{Age modifier}

Maximum stand age used to computer relative age

Power of relative age in $f_{\text {age }}$

Relative age to give $f_{\text {age }}=0.5$

\section{Conductance}

Maximum canopy conductance

Canopy LAI for maximum canopy conductance

Canopy boundary layer conductance

\section{Canopy structure and processes}

\section{Specific leaf area}

Specific leaf area at stand age 0

Specific leaf area for mature aged stands

Age at which specific leaf area $=1 / 2\left(\sigma_{0}+\sigma_{1}\right)$

\section{Rainfall interception}

Maximum fraction of rainfall intercepted by canopy

LAI for maximum rainfall interception

\section{Light interception, production and respiration}

Extinction coefficient for PAR absorption by canopy

Age at full canopy cover

Maximum canopy quantum efficiency

Ratio NPP/GPP

\section{Wood and stand properties}

\section{Basic density}

Minimum basic density_-for young trees

Maximum basic density - for older trees

Age at which $\rho=1 / 2$ density of old and young trees

\section{Conversion factors}

Intercept of net radiation and solar radiation relationship

Slope of net radiation and solar radiation relationship

Molecular weight of dry matter

Conversion of solar radiation to PAR
Symbol

Units

$m_{0}$
$f_{N 0}$
$n_{f N}$

$\boldsymbol{k}_{\boldsymbol{D}}$

mbar

$\boldsymbol{c}_{\theta}$

$\boldsymbol{n}_{\theta}$

$t_{x}$

yr

$\boldsymbol{n}_{\text {age }}$

$r_{\text {age }}$

$g_{C x}$

$L_{C x}$

$\mathrm{m} \mathrm{s}^{-1}$

$g_{B}$

$\mathrm{m}^{2} \mathrm{~m}^{-2}$

$\mathrm{m} \mathrm{s}^{-1}$

$\sigma_{0}$

$\mathrm{m}^{2} \mathrm{~kg}^{-1}$

$\sigma_{1}$

$\boldsymbol{t}_{\sigma}$

$\mathrm{m}^{2} \mathrm{~kg}^{-1}$

yr

$i_{R x}$

$L_{i x}$

$\mathrm{m}^{2} \mathrm{~m}^{-2}$

\section{$k$}

$\boldsymbol{t}_{c}$

$\alpha_{C x}$

$Y$

\begin{tabular}{lc}
$\boldsymbol{\rho}_{\mathbf{0}}$ & $\mathrm{t} \mathrm{m}^{-3}$ \\
$\boldsymbol{\rho}_{\mathbf{1}}$ & $\mathrm{t} \mathrm{m}^{-3}$ \\
$\boldsymbol{t} \boldsymbol{\rho}$ & $\mathrm{yr}$ \\
\hline
\end{tabular}

$Q_{a}$

$\mathrm{W} \mathrm{m}{ }^{-2}$

$Q_{b}$

$\mathrm{g} \mathrm{mol}^{-1}$

$\mathrm{mol} \mathrm{MJ}^{-1}$ 


\subsection{Data Outputs}

The outputs are primarily foliage, root, and stem biomass $\left(W_{F}, W_{R}\right.$, and $\left.W_{S}: \mathrm{t} \mathrm{ha}^{-1}\right)$, gross primary productivity (GPP: $\mathrm{t} \mathrm{ha}^{-1}$ ), and net primary productivity (NPP: $\mathrm{t} \mathrm{ha}^{-1}$ ). Other stand-level outputs can be leaf area index $(L A I)$, specific leaf area $(S L A)$, stem volume $\left(V: \mathrm{m}^{3} \mathrm{ha}^{-1}\right)$, stem number $\left(N\right.$ : trees ha $\left.{ }^{-1}\right)$, average stem diameter at breast height $(B: \mathrm{cm})$, and mean annual stem-volume increment (MAI: $\mathrm{m}^{3} \mathrm{ha}^{-1} \mathrm{year}^{-1}$ ). 3-PG outputs can be estimated monthly or annually, as well as over longer periods.

\subsection{Major Elements of the 3-PG Model for Parameterization}

In this study, we focused on parameterization of deciduous broadleaf forests for GPP. The species-specific parameters involved in estimating GPP are part of biomass partitioning and biomass production. Biomass partitioning is related to biomass allocation to the stem, foliage, and roots, each of which is influenced by the GPP. Biomass partitioning is controlled by the ratio of foliage to stem biomass allocation. Root biomass allocation is influenced by soil nutrition and available soil water. However, root data were not available in this study. The partitioning ratio between foliage biomass and stem biomass $(p F S)$ is a function of stem diameter, as shown in the allometric relationship in Equation (1):

$$
p F S=a_{p} B^{n p}
$$

where $B$ is diameter at breast height $(D B H), a_{p}=a_{F} n_{F} a_{s} n_{s}$, and $n_{p}=n_{F}-n_{s}$. Both $a_{p}$ and $n_{p}$ are expressed in terms of $p F S_{2}$ and $p F S_{20}$. Generally, $p F S_{2}$ and $p F S_{20}$ are extracted for $B$ values of 2 and $20 \mathrm{~cm}$, respectively [10].

To obtain $a_{s}$ and $n_{s}$ (Equation (2)), we determine the relationship between $W s$ and $B$ by fitting the allometric relationship from the observed data. $a_{F}$ and $n_{F}$ (Equation (3)) are from the allometric relationship between $W_{F}$ and $B$.

$$
\begin{gathered}
W s=a_{s} B^{n s} \\
W_{F}=a_{F} B^{n F}
\end{gathered}
$$

In biomass production, growth modifiers directly influence GPP. This modification accounts for environmental conditions affecting forest growth. The six growth modifiers are temperature $\left(f_{T}\right)$, frost day $\left(f_{F}\right)$, site nutrition $\left(f_{N}\right)$, available soil water $\left(f_{\theta}\right)$, vapor pressure deficit $\left(f_{D}\right)$, and stand age $\left(f_{A G E}\right)$. The value of each modifier ranges from 0 to 1 . As a modifier approaches 0 , it has a stronger influence on forest growth $[8,10]$. Temperature and frost effects control biomass production in this study area. The equations describing each modifier are as follows. The other modifiers have been reported by Landsberg and Waring [8].

\subsection{Temperature Modifier}

This parameter is given by the expression:

$$
f_{T}=\left[\left(T_{a}-T_{n}\right) /\left(T_{o p t}-T_{n}\right)\right]\left[\left(T_{x}-T_{a}\right) /\left(T_{x}-T_{o p t}\right)\right]^{(T x-T o p t) /(T o p t-T n)}
$$


where $T_{a}$ is monthly mean temperature (the actual value for each month), and $T_{n}, T_{o p t}$, and $T_{x}$ are the minimum, optimum, and maximum temperatures for forest growth, respectively. If $T_{a} \leq T_{n}$ or $T_{a} \geq T_{x}$, $f_{T}$ becomes 0 .

\subsection{Frost Day Modifier}

This parameter is calculated by the expression:

$$
f_{F}=1-k_{F}\left(d_{f} / 30\right)
$$

where $k_{F}$ is the number of days of production lost for each frost day, and $d_{f}$ (day month ${ }^{-1}$ ) is the mean number of frost days per month. If frost does not occur at the site, then $f_{F}=1$. Note that the number shown above as 30 changes according to the number of days in each month.

GPP is calculated as shown in Equation (6), by converting absorbed photosynthetically active radiation (APAR, $\phi_{p a}$ ) to GPP using the canopy quantum efficiency $\left(\alpha_{C}\right)$, which is constrained by the growth modifiers $[8,10]$ :

$$
\alpha_{C}=\alpha_{C x} \varphi f_{T} f_{F} f_{N}
$$

where $\alpha_{C x}$ is the maximum canopy quantum efficiency, and $f_{T}, f_{F}$, and $f_{N}$ are the temperature, frost day, and site nutrition modifiers, respectively. $\varphi$ (Equation (7)) is a physiological modifier that is determined by the minimum vapor pressure deficit $\left(f_{D}\right)$ and available soil water modifiers $\left(f_{\theta}\right)$ multiplied by the stand age modifier $\left(f_{\text {age }}\right)$ :

$$
\varphi=f_{\text {age }} \min \left\{f_{D}, f_{\theta}\right\}
$$

Then, GPP is estimated using Equation (8):

$$
G P P=f_{T} f_{F} f_{N} \alpha_{C x} \varphi \phi_{p a}
$$

where $\phi_{p a}$ is APAR calculated using Beer's Law using intercepted solar radiation based on LAI for photosynthesis. NPP is a constant fraction of GPP multiplied by $0.47 \pm 0.4[17,18]$.

\section{Materials and Methods}

\subsection{Site Description}

We collected data at two study sites, Hitsujigaoka and Takayama. Hitsujigaoka is located in northern Japan at $42^{\circ} 59^{\prime} 13^{\prime \prime} \mathrm{N}$ and $141^{\circ} 23^{\prime} 7^{\prime \prime} \mathrm{E}$ and is $180 \mathrm{~m}$ above sea level. Takayama is in central Japan at $36^{\circ} 8^{\prime} 46^{\prime \prime} \mathrm{N}$ and $137^{\circ} 25^{\prime} 23^{\prime \prime} \mathrm{E}$ and is 1,420 m above sea level. At each site, a flux tower collected meteorological data and ecological characteristics. Averaged over five years, from 2001 to 2006 (Figure 1), the maximum temperatures at Hitsugaoka and Takayama were $24.9 \pm 1.8^{\circ} \mathrm{C}$ and $22.4 \pm 1.6{ }^{\circ} \mathrm{C}$ in August, while the minimum temperatures were $-12.4 \pm 1.7{ }^{\circ} \mathrm{C}$ and $-11.7 \pm 2.1^{\circ} \mathrm{C}$ in February, respectively. The mean annual precipitation and mean annual solar radiation at Hitsujigaoka were $1,047 \pm 174 \mathrm{~mm}$ and $12.25 \pm 0.4 \mathrm{MJ} \mathrm{m}^{-2}$ day $^{-1}$, respectively, whereas at Takayama they were $2,275 \pm 165 \mathrm{~mm}$ and $12.43 \pm 0.3 \mathrm{MJ} \mathrm{m}^{-2}$ day $^{-1}$, respectively. Both sites experience snow cover in the winter (December to April) to a depth of $1 \mathrm{~m}$. 
Figure 1. Average monthly meteorological data from 2001-2006 as (a) temperature in terms of minimum temperature at Hitsujigaoka (open rectangular and dashed line) and Takayama (open circle and dashed line), and maximum temperature at Hitsujigaoka (solid rectangular and solid line) and Takayama (solid circle and solid line); (b) precipitation at Hitsujigaoka (solid bar) and Takayama (open bar); and (c) solar radiation at Hitsujigaoka (solid rectangular and dashed line) and Takayama (solid circle and solid line).
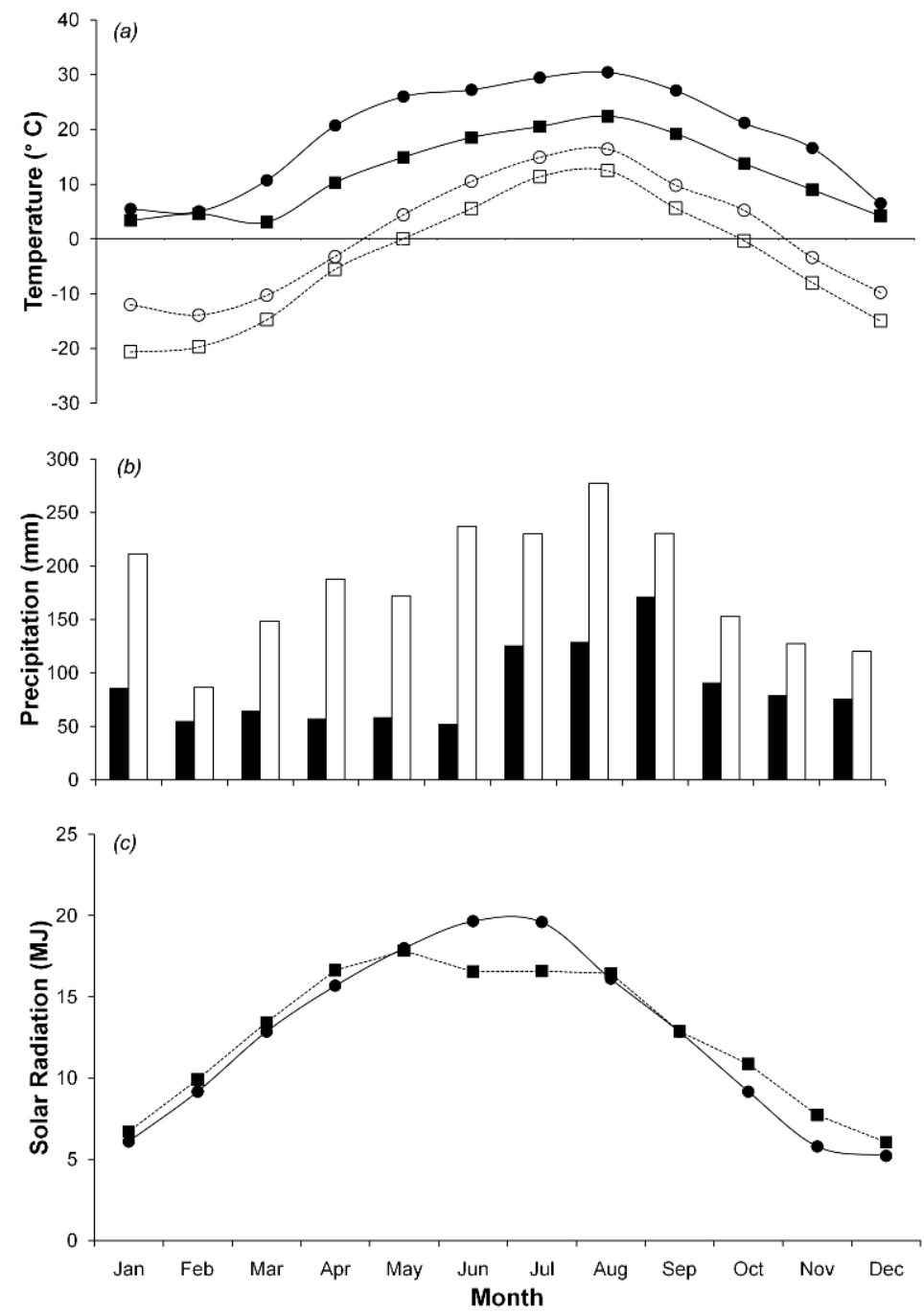

The main vegetation type was deciduous broadleaf natural forest, and the dominant species was Betula platyphylla. The stand basal area for this species accounted for around $81 \%$ and $63 \%$ of the total basal area at Hitsujigaoka and Takayama, respectively. Tree height ranged from 14 to $28 \mathrm{~m}$. Overstory trees at Hitsujigaoka (around 100 years) were older than those at Takayama (around 50 years; [19,20]). The mean DBH was larger at Hitsujigaoka $(23.0 \mathrm{~cm})$ than at Takayama $(11.4 \mathrm{~cm}$; [19]). We note that the flux tower at Hitsujigaoka was compromised and the forest around the flux tower was severely damaged by a typhoon in 2003. Data from Takayama were used for calibration, while data from Hitsujigaoka were used for validation. The different locations did not significantly influence the model output because the two sites are located in the same climatic zone and are characterized by the same canopy species. Site data is summarized in Table 2. 
Table 2. Summary of the site description at Takayama and Hitsujigaoka.

\begin{tabular}{lcc}
\hline & Takayama & Hitsujigaoka \\
\hline Latitude & $36^{\circ} 8^{\prime} 46^{\prime \prime} \mathrm{N}$ & $42^{\circ} 59^{\prime} 13^{\prime \prime} \mathrm{N}$ \\
Longitude & $137^{\circ} 25^{\prime} 23^{\prime \prime} \mathrm{E}$ & $141^{\circ} 23^{\prime} 7^{\prime \prime} \mathrm{E}$ \\
Maximum Temperature $\left({ }^{\circ} \mathrm{C}\right)$ & 22.4 & 24.9 \\
Minimum Temperature $\left({ }^{\circ} \mathrm{C}\right)$ & -11.7 & -12.4 \\
Precipitation $(\mathrm{mm})$ & 2,275 & 1,047 \\
Solar Radiation $\left(\mathrm{MJ} \mathrm{m}^{-2} \mathrm{day}^{-1}\right)$ & 12.43 & 12.25 \\
Dominant Species & Betula platyphylla & Betula platyphylla \\
Average Canopy Age (year) & 50 & 100 \\
Mean DBH (cm) & 11.4 & 23 \\
Mean Tree Height $(\mathrm{m})$ & 22 & 24 \\
\hline
\end{tabular}

\subsection{Flux Tower Measurements}

Each site has two flux towers. The first tower continuously monitored meteorological data. The second monitored only ecological properties. Meteorological data, including air temperature, precipitation, global solar radiation, humidity, wind speed, and soil temperature were collected every 30 min. The 3-PG model requires data on air temperature, precipitation, and solar radiation. Figure 1 shows monthly meteorological data, which were used as input parameters, for Hitsujigaoka and Takayama from 2001-2006. Vapor pressure deficit was calculated based on maximum and minimum temperatures. Days when the temperature was below $2{ }^{\circ} \mathrm{C}$ were counted as frost days. $\mathrm{CO}_{2}$ flux was measured by the eddy covariance method [21]. These data were collected in 30-min increments and used to validate the results. $\mathrm{CO}_{2}$ flux was used to estimate net ecosystem exchange (NEE). Then, GPP was estimated by NEE and ecosystem respiration. Canopy respiration was not observed in the study, therefore NPP is not available.

\subsection{Parameterization for Deciduous Broadleaf Forests}

\subsubsection{Biomass Partitioning}

Tree canopy properties were measured in a $100 \mathrm{~m} \times 100 \mathrm{~m}$ permanent plot near the flux tower at Takayama [19]. Within the plot, 24 trees (comprising several species) were selected to measure DBH, height, and tree density. Trees with DBH from 1.7 to $29.0 \mathrm{~cm}$ were selected to represent the different stand ages, because the actual stand age was not identified. Nine of the 24 sampled trees were B. platyphylla, with a range of small to large $\mathrm{DBH}$. The different DBHs can be used to predict forest growth. The trees were harvested for biomass calculation using the dry mass of the stem and the foliage. Data for B. platyphylla were used for parameterization in biomass partitioning. Figure 2a shows the allometric relationship between DBH and stem biomass. Figure $2 b$ shows the allometric relationship between DBH and foliage biomass. The allometric parameters gave an excellent fit to the trend lines, with $r^{2}=0.97$ and 0.98 for stem and foliage biomass, respectively. The equations in Figure 2 were used to re-estimate stem and foliage biomass at Hitsujigaoka for validation. The results are shown in Figure 3, where the plots of estimated versus observed stem and foliage biomass were 
close to one-to-one linear relationships. Stem biomass was underestimated by around $3 \%$, whereas foliage biomass was overestimated by about $15 \%$.

Figure 2. Allometric relationship between (a) stem biomass and DBH (open circle); and (b) foliage biomass and DBH (solid rectangular) at Takayama. The allometric equation of stem biomass and DBH is $y=0.049 x^{2.64}$, while foliage biomass and DBH is $y=0.002 x^{2.56}$. The values from the allometric equation were used to calculate the parameter values in the biomass partitioning.
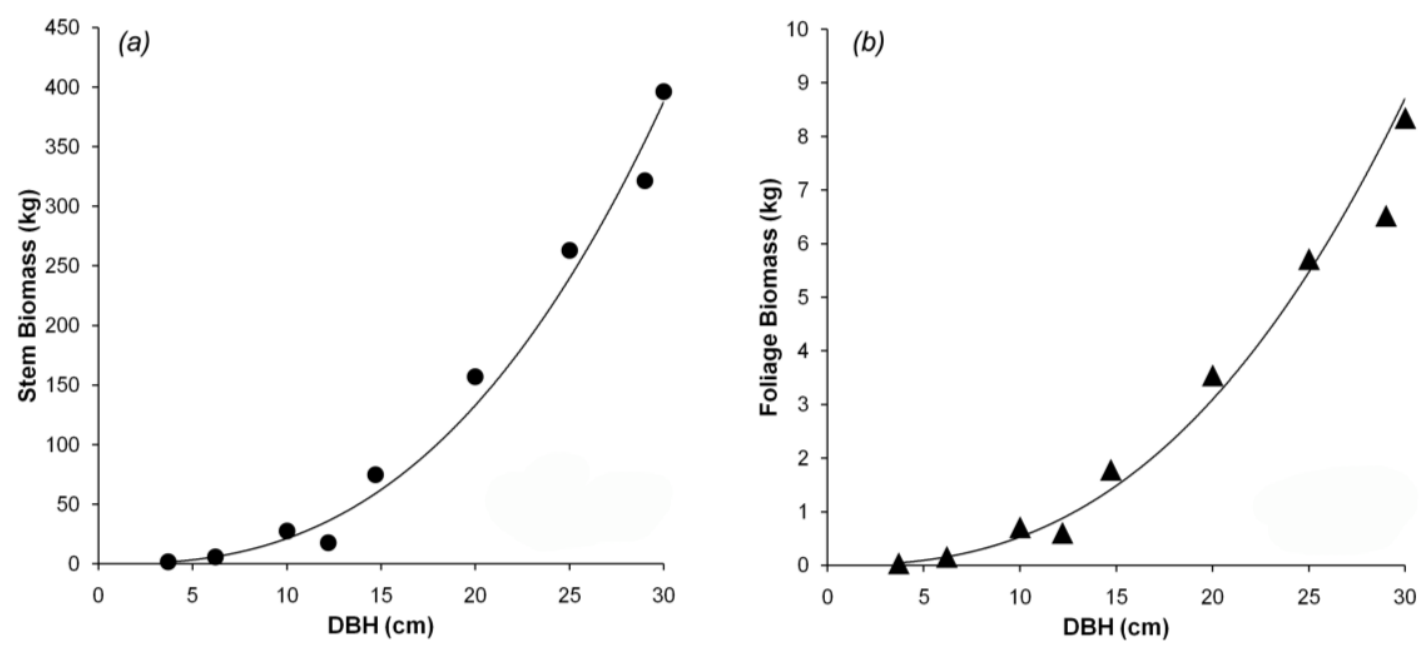

Figure 3. The estimated biomass versus the observed biomass at Hitsujigaoka for validation, the estimated values equal the observed values, (a) stem biomass (open circle); and (b) foliage biomass (open triangle). The linear regression showed $y=0.98 x-1.60$ for stem biomass, and $\mathrm{y}=1.15 \mathrm{x}-0.04$ for foliage biomass, respectively.
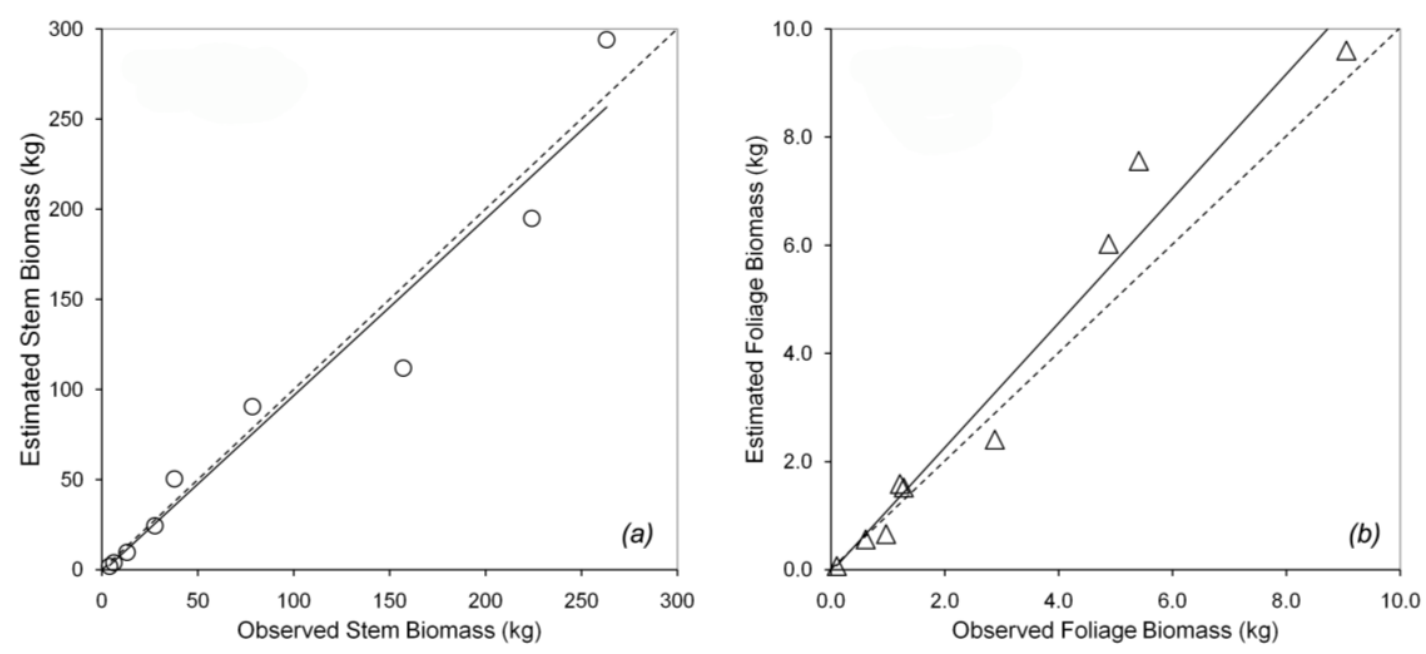

From those relationships, $a_{s}, n_{s}, a_{F}$, and $n_{F}$ were calculated as $0.049,2.64,0.002$, and 2.56, respectively $\left(\mathrm{r}^{2}=0.97\right.$ for stem biomass and 0.98 for foliage biomass). Based on the allometric relationships, $a_{P}$ and $n_{P}$ were computed by substituting $a_{s}, n_{s}, a_{F}$, and $n_{F}$, to retrieve $a_{P}$ and $n_{P} . p F S 2$ and pFS2O were 0.03 and 0.02 , respectively, in these deciduous broadleaf forests of $B$. platyphylla. 


\subsubsection{Growth Modifiers}

GPP was influenced by LAI and solar radiation, as well as environmental conditions, especially temperature. Figure 4a plots observed GPP with average temperature, solar radiation, and LAI throughout the year. GPP occurred from May to October and was highest in July. Conversely, there was no GPP from November to April. GPP responded to leaf phenology, with leaves emerging in May and falling in November. Solar radiation and LAI peaked in July, resulting in high levels of intercepted solar radiation (Figure 4b) and maximum GPP. The temperature modifier affected quantum efficiency. Figure 5 shows the relationship between mean annual temperature and the temperature modifier to determine $T_{n}, T_{\text {opt }}$, and $T_{x}$ for growth. Thus, in this study, $T_{n}, T_{o p t}$, and $T_{x}$ were $8.5{ }^{\circ} \mathrm{C}, 24.5^{\circ} \mathrm{C}$, and $36{ }^{\circ} \mathrm{C}$, respectively. If the mean temperature was less than $T_{n}$ or greater than $T_{x}, \alpha_{C}$ was 0 and caused GPP to also be 0 .

Figure 4. Comparison among (a) monthly gross primary productivity (solid bar) with mean monthly temperature (solid line), monthly solar radiation (small dashed line) and monthly LAI (big dashed line); (b) monthly gross primary productivity (solid bar) with monthly intercepted radiation (dashed line).
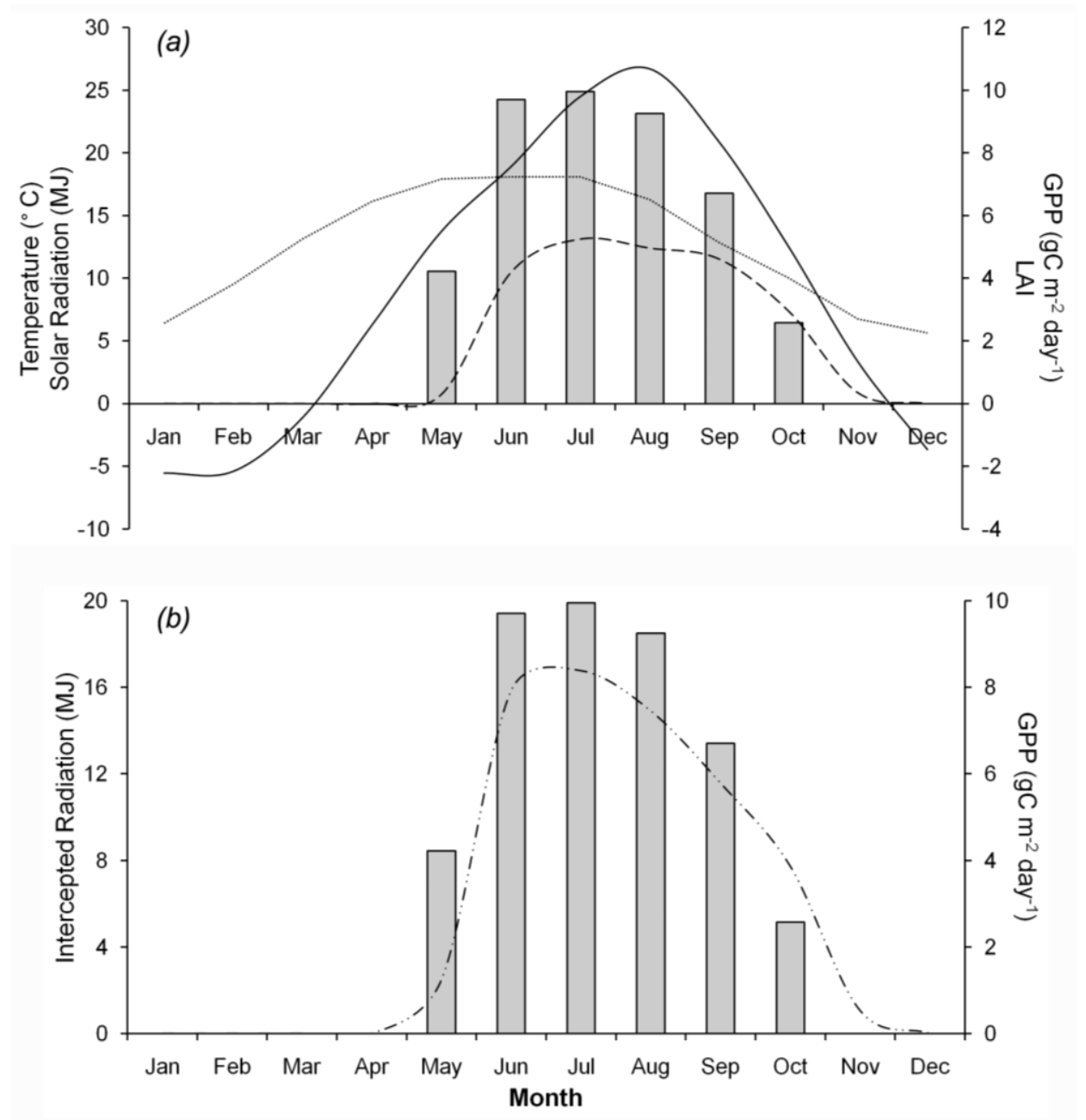
Figure 5. Appearance of the temperature modifier $\left(\mathrm{f}_{\mathrm{T}}\right)$. Point fitted (open circle) were determined by fitting 3-PG to data from Takayama. The line observed (solid line) is a fit of the data to the equation of temperature modifier.

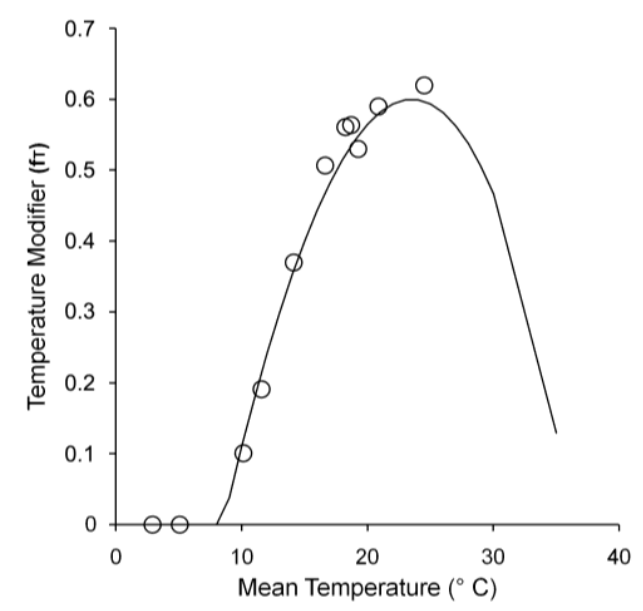

\subsubsection{Other Parameters}

Other parameters related to biomass production were assigned values based on direct field measurements. If data were not available for parameterization, a best-fit method was applied by tuning the parameter to obtain an output that corresponded with observed data.

LAI data were obtained using the fish-eye camera method with a Nikon CoolPix camera fitted with a fish-eye lens (Nikon FC-E8). Photos were automatically taken every 2 min during the day and those from 2004 to 2006 were used [22]. Clear sky condition photographs were selected to calculate LAI. LAI data were used to initialize specific leaf area. Litterfall data were collected using 14 traps in a $100 \mathrm{~m} \times 100 \mathrm{~m}$ area. Each trap was $1 \mathrm{~m}^{2}$ and was set up for the entire growing season. Tree canopy density was counted based on the amount of tree canopy within the permanent plot. The ratio of NPP/GPP was used to convert GPP to NPP [23]. Note that sites were not constrained by site nutrition or available soil water factors. Parameter values not available for biomass partitioning and biomass production were set as the default values based on the original 3-PG model and did not significantly affect output. All parameter values derived in this study are presented in Table 3.

\subsection{Sensitivity Analysis}

A sensitivity analysis was carried out to examine how parameter values influenced the output. The parameters examined were $a_{s}$ and $n_{s}$, biomass partitioning ratio at $\mathrm{B}=2$ and $20 \mathrm{~cm}$, maximum canopy quantum efficiency $\left(\alpha_{C x}\right), T_{n}$, and $T_{o p t}$. These are the main parameters of biomass partitioning and biomass production, and the most influential for GPP estimation. We determined the effects of changes in these parameters on $W_{s}, W_{f}$, and GPP. Additionally, sensitivity to meteorological data was analyzed with the GPP results. The parameter values changed by $-20 \%,-10 \%,+10 \%$, and $+20 \%$ from the default values, except for temperature, which was changed to degrees Celsius $\left(-2{ }^{\circ} \mathrm{C},-1{ }^{\circ} \mathrm{C},+1{ }^{\circ} \mathrm{C}\right.$, and $+2{ }^{\circ} \mathrm{C}$ ) since changes in degrees Celsius usually showed a more significant effect than those in percentage. 
Table 3. List of parameter values as used in 3-PG for deciduous broadleaf forest. Most data are observed $(\mathrm{O})$ from the experimental plot data and the others were obtained from the literature $(\mathrm{L})$.

\begin{tabular}{|c|c|c|c|c|}
\hline Description of parameter & Symbol & Units & Default Value & $\mathrm{O} / \mathrm{L}$ \\
\hline \multicolumn{5}{|l|}{ Allometric relationships \& partitioning } \\
\hline Ratio of foliage:stem partitioning at $B=2 \mathrm{~cm}$ & $p F S_{2}$ & - & 0.03 & $\mathrm{O}$ \\
\hline Ratio of foliage:stem partitioning at $B=20 \mathrm{~cm}$ & $p F S_{20}$ & - & 0.02 & $\mathrm{O}$ \\
\hline Constant in stem mass $v$ diam. relationship & $a_{S}$ & - & 0.06 & $\mathrm{O}$ \\
\hline Power in stem mass $v$ diam. relationship & $\boldsymbol{n}_{S}$ & - & 2.6 & $\mathrm{O}$ \\
\hline \multicolumn{5}{|l|}{ Litterfall \& root turnover } \\
\hline Litterfall rate at $t=0$ & $F 0$ & month $^{-1}$ & 0.083 & $\mathrm{O}$ \\
\hline Litterfall rate for mature stands & $F 1$ & month $^{-1}$ & 0.083 & $\mathrm{O}$ \\
\hline Age at which litterfall rate has median value & $t_{F}$ & month & 24 & $\mathrm{O}$ \\
\hline Average monthly root turnover rate & $R$ & month $^{-1}$ & 0.083 & $\mathrm{~L}$ \\
\hline \multicolumn{5}{|l|}{ Temperature modifier } \\
\hline Minimum temperature for growth & $T_{n}$ & ${ }^{\circ} \mathrm{C}$ & 8.5 & $\mathrm{O}$ \\
\hline Optimum temperature for growth & $T_{\text {opt }}$ & ${ }^{\circ} \mathrm{C}$ & 24.5 & $\mathrm{O}$ \\
\hline Maximum temperature for growth & $T_{x}$ & ${ }^{\circ} \mathrm{C}$ & 36 & $\mathrm{O}$ \\
\hline \multicolumn{5}{|l|}{ Frost modifier } \\
\hline Number of days production lost for each frost day & $k_{F}$ & days & 1 & $\mathrm{O}$ \\
\hline \multicolumn{5}{|l|}{ VPD modifier } \\
\hline Defines stomatal response to VPD & $k_{D}$ & mbar & 0.05 & $\mathrm{O}$ \\
\hline \multicolumn{5}{|l|}{ Stem Number } \\
\hline Basic density & $\rho$ & $\mathrm{t} \mathrm{m}^{-3}$ & 0.6 & $\mathrm{O}$ \\
\hline Maximum tree stem mass for 1,000 trees $\mathrm{ha}^{-1}$ & $w_{S x \mathbf{1 0 0 0}}$ & $\mathrm{kg}$ tree $^{-1}$ & 180 & $\mathrm{O}$ \\
\hline \multicolumn{5}{|l|}{ Conductance } \\
\hline Maximum canopy conductance & $g_{C x}$ & $\mathrm{~m} \mathrm{~s}^{-1}$ & 0.02 & $\mathrm{O}$ \\
\hline Canopy LAI for maximum canopy conductance & $L_{C x}$ & $\mathrm{~m}^{2} \mathrm{~m}^{-2}$ & 3.33 & $\mathrm{O}$ \\
\hline \multicolumn{5}{|l|}{ Specific leaf area } \\
\hline Specific leaf area at stand age 0 & $\sigma_{0}$ & $\mathrm{~m}^{2} \mathrm{~kg}^{-1}$ & 16 & $\mathrm{~L}$ \\
\hline Specific leaf area for mature aged stands & $\sigma_{1}$ & $\mathrm{~m}^{2} \mathrm{~kg}^{-1}$ & 16 & $\mathrm{~L}$ \\
\hline Age at which specific leaf area $=1 / 2\left(\sigma_{0}+\sigma_{1}\right)$ & $t_{\sigma}$ & $\mathrm{yr}$ & 2.5 & $\mathrm{~L}$ \\
\hline \multicolumn{5}{|l|}{ Light interception, production and respiration } \\
\hline Extinction coefficient for PAR absorption by canopy & $\boldsymbol{k}$ & - & 0.565 & $\mathrm{O}$ \\
\hline Maximum canopy quantum efficiency & $\alpha_{C x}$ & - & 0.012 & $\mathrm{O}$ \\
\hline Ratio NPP/GPP & $Y$ & - & 0.422 & $\mathrm{O}$ \\
\hline
\end{tabular}

\section{Results}

Because the study site was a mature forest we do not present an age-series analysis. In this study, we were interested in biomass production because biomass directly relates to the amount of carbon stored by the tree canopy. Our results were validated with the observed data, and a linear regression was applied to investigate accuracy. 


\subsection{Biomass Calculation}

Biomass can be divided into three parts: stem, foliage, and root biomass. We did not examine root biomass because empirical data were not available. Figure 6 shows the estimated stem and foliage biomass versus the observed biomass at each site. Both relationships were close to one-to-one linear relationships. Linear regression showed a high correlation between the estimated and observed values $\left(\mathrm{r}^{2}=0.89\right.$ and 0.94 for stem and foliage biomass, respectively). These values were close to the one-to-one line, in which the estimated values should be equal to the observed values. Foliage and stem biomass at Takayama were slightly overestimated compared to those at Hitsujigaoka. This difference was likely because the canopy at Takayama is younger than that at Hitsujigaoka. A summary of regression statistics is given in Table 4 .

Figure 6. Validation of (a) estimated stem biomass versus observed stem biomass at Hitsujigaoka (open circle) and Takayama (solid circle); and (b) estimated foliage biomass versus observed foliage biomass at Hitsujigaoka (open triangle) and Takayama (solid triangle). The estimated values equal the observed values.
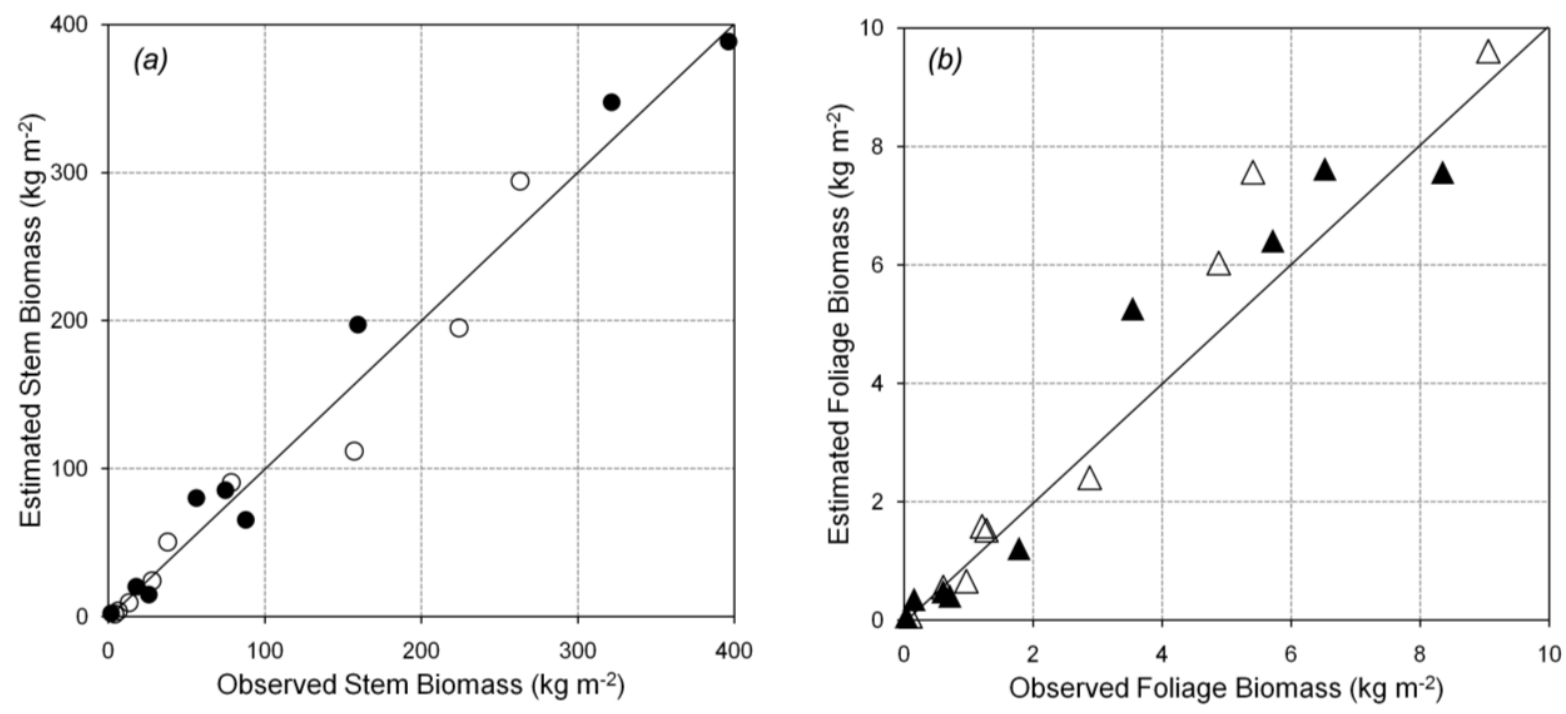

Table 4. Summary of linear regression statistics of estimated versus observed values of stem biomass $\left(\mathrm{W}_{\mathrm{s}}\right)$, foliage biomass $\left(\mathrm{W}_{\mathrm{F}}\right)$ and GPP at Hitsujigaoka $(\mathrm{HTJ})$ and Takayama (TKY). The error terms were presented as the standard deviation values.

\begin{tabular}{cccccc}
\hline Parameters & Site & N & Equation & RMSE & Standard deviation \\
\hline$W_{s}$ & HTJ & 9 & $0.98 \mathrm{X}-1.59$ & 0.95 & 14.40 \\
& TKY & 9 & $1.02 \mathrm{X}+3.79$ & 0.96 & 12.66 \\
\multirow{4}{*}{$W_{F}$} & All & 18 & $1.01 \mathrm{X}+0.02$ & 0.94 & 16.22 \\
& HTJ & 9 & $1.15 \mathrm{X}-0.04$ & 0.96 & 0.25 \\
& TKY & 9 & $1.04 \mathrm{X}-0.07$ & 0.94 & 0.26 \\
GPP & All & 18 & $1.09 \mathrm{X}+0.02$ & 0.89 & 0.28 \\
& HTJ & 24 & $1.13 \mathrm{X}+0.22$ & 0.97 & 3.21 \\
& TKY & 60 & $0.86 \mathrm{X}-0.34$ & 0.85 & 4.01 \\
\hline
\end{tabular}




\subsection{Gross Primary Productivity}

The GPP estimation at Hitsujigaoka and Takayama is presented in Figure $7 \mathrm{a}$ and $7 \mathrm{~b}$, respectively. The monthly estimated GPP was compared with the observed GPP from 2000 to 2004. The results for both locations showed a good correlation in terms of the linear regression, with $r^{2}=0.85$ and 0.97 at Takayama and Hitsujigoaka, respectively. The 3-PG model indicated that inter-annual GPP peaked around July and August and was 0 in winter (November to April). GPP was lower at Takayama than at Hitsujigaoka because of the smaller LAI at Takayama. Thus, the interception of radiation was lower at Takayama. The GPP at Takayama was underestimated because of the mixed age of the trees in the plot and the influence of the temperature modifier. The low value of the latter at the beginning of the growing season resulted in the low estimate for GPP (low points in the graph). At Hitsujigaoka, the GPP was overestimated because the large tree leaves could absorb more solar radiation for photosynthesis. The average GPP over 5 years was $973.30 \mathrm{~g} \mathrm{C} \mathrm{m}^{-2}$ (Takayama) and $1255.21 \mathrm{~g} \mathrm{C} \mathrm{m}^{-2}$ (Hitsujigaoka). Table 4 compares the estimated and observed values of GPP in terms of root mean square error.

Figure 7. Comparison of estimated GPP and observed GPP from flux tower at (a) Takayama and (b) Hitsujigaoka, respectively. The dash line is the linear regression between the estimated and observed value. At Takayama, the linear equation is $\mathrm{y}=0.855 \mathrm{x}-0.339$, and at Hitsujigaoka is $\mathrm{y}=1.125 \mathrm{x}+0.217$, respectively.
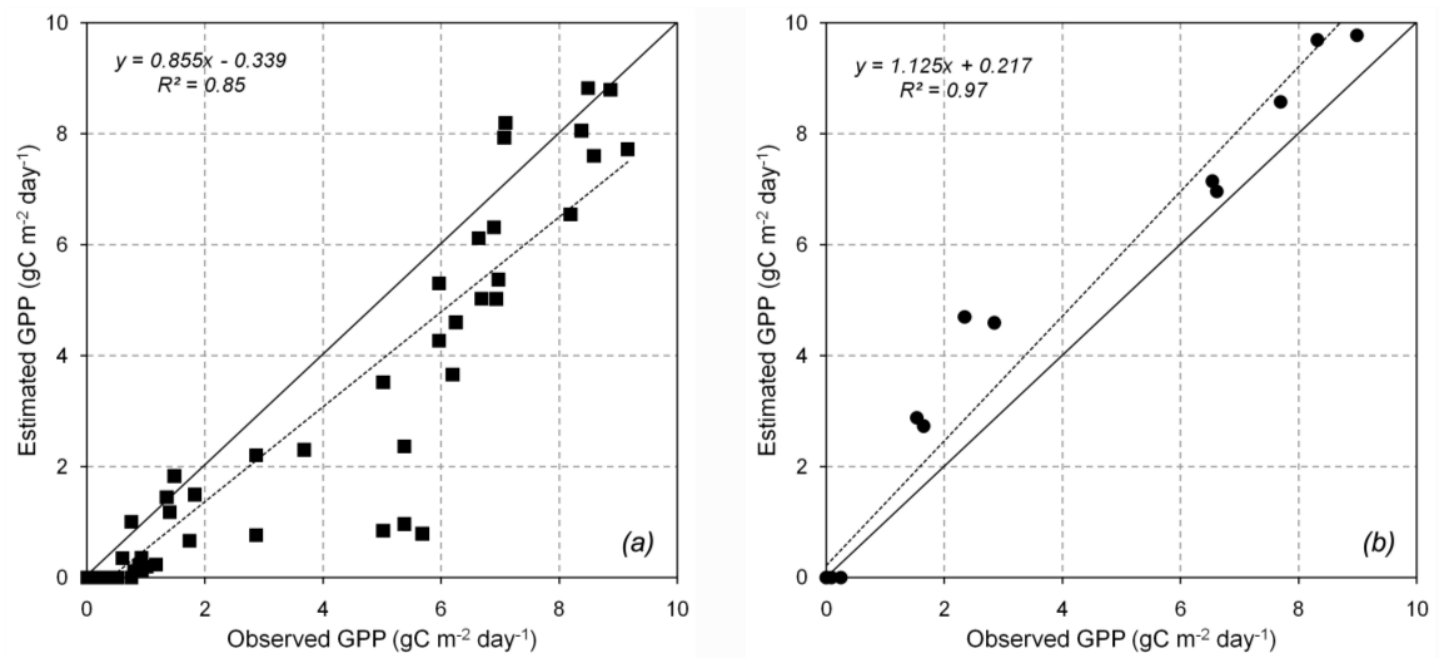

\subsection{Sensitivity Analysis}

Changing selected parameter values from -20 to $20 \%$ had different effects on the estimated output. Figure 8 shows the effects of changes in $a_{s}, n_{s}, p F S 2, p F S 20, \alpha_{C x}, T_{n}, T_{o p t}, W_{F}$, and $W_{s}$. Changes in $a_{s}$ (Figure 8a) and $n_{s}$ (Figure 8b) primarily affected $W_{F}$; when $a_{s}$ and $n_{s}$ were changed by $-20 \%, W_{F}$ differed by around $16 \%$ and $6 \%$, respectively. However, the selected outputs were less sensitive to changes in pFS2O (Figure 8d) than pFS2 (Figure 8c). GPP was highly sensitive to $\alpha_{C x}$ (Figure 8e) and to $T_{\text {opt }}$ (Figure 8f). $W_{s}$ was also sensitive to both of those parameters, but not as sensitive as GPP. $T_{n}$ (Figure $8 \mathrm{~g}$ ) most affected GPP when it was changed by $20^{\circ} \mathrm{C}$. From these results, we recommend that $\alpha_{C x}, T_{o p t}$, and $T_{n}$ be carefully measured if accurate results are desired, especially in GPP calculations. 
Figure 8. Sensitivity analysis of selected 3-PG outputs by changed the value of (a) stem constant: $a_{s}$; (b) stem power: $n_{s}$; (c) biomass partitioning ratio at $\mathrm{DBH}=2 \mathrm{~cm}$ : $p F S 2$ and (d) $\mathrm{DBH}=20 \mathrm{~cm}$ : $p F S 20$; (e) maximum canopy quantum efficiency: $\alpha_{C x}$; (f) optimum temperature: Topt; and (g) minimum temperature: Tmin. The effect on the following output as stem biomass (black bar), foliage biomass (grey bar) and GPP (open bar) by changed the parameter value differed from -20 to $20 \%$, with $10 \%$ interval. For both of Topt and Tmin, they were changed in degree Celsius as $-2{ }^{\circ} \mathrm{C},-1{ }^{\circ} \mathrm{C},+1{ }^{\circ} \mathrm{C}$, and $+2{ }^{\circ} \mathrm{C}$.
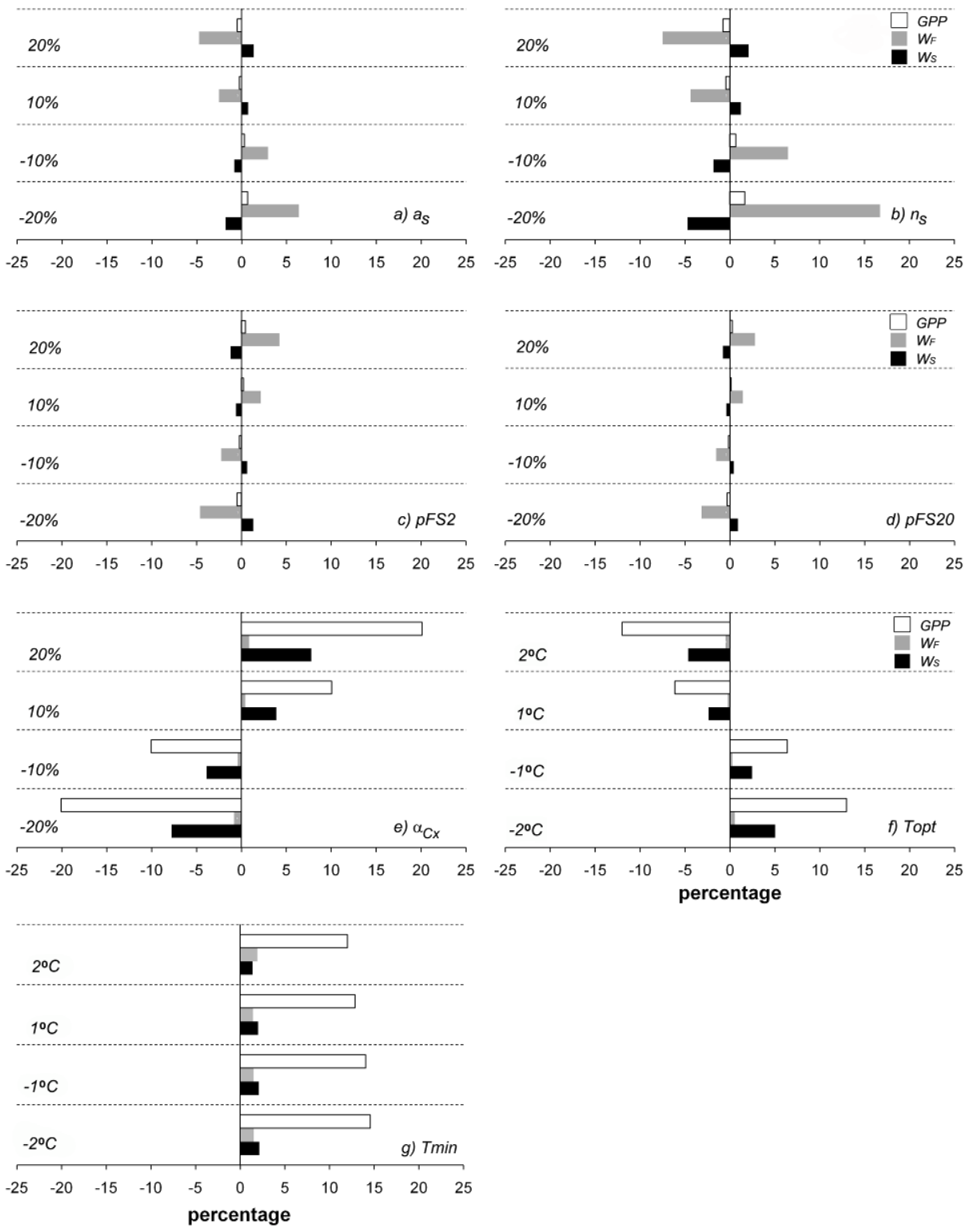

Figure 9 shows the effects of meteorological data on GPP. Solar radiation (Figure 9b) and $T_{n}$ (Figure 9a) had significant impacts on GPP, with differences around $\pm 3 \mathrm{~g} \mathrm{C} \mathrm{m}^{-2}$, but $T_{x}$ had only a slight effect (Figure 9a). Increased solar radiation and $T_{n}$ increased GPP. However, GPP was not sensitive to frost days or precipitation, since the study sites are not limited by water. Snow melt increases the soil water content in the summer. The effect of frost days on GPP was large in the winter, as large as the effect of temperature. However, frost days did not affect GPP in the summer, during which GPP was most affected by temperature and solar radiation. 
Figure 9. Effect of meteorological data on GPP as following (a) minimum temperature (open circle and dashed line) and maximum temperature (solid circle and solid line); (b) solar radiation The parameter values were changed $-20 \%,-10 \%,+10 \%$, and $+20 \%$, except for temperature, which was changed in degrees Celsius $\left(-2{ }^{\circ} \mathrm{C},-1{ }^{\circ} \mathrm{C},+1{ }^{\circ} \mathrm{C}\right.$, and $\left.+2{ }^{\circ} \mathrm{C}\right)$.
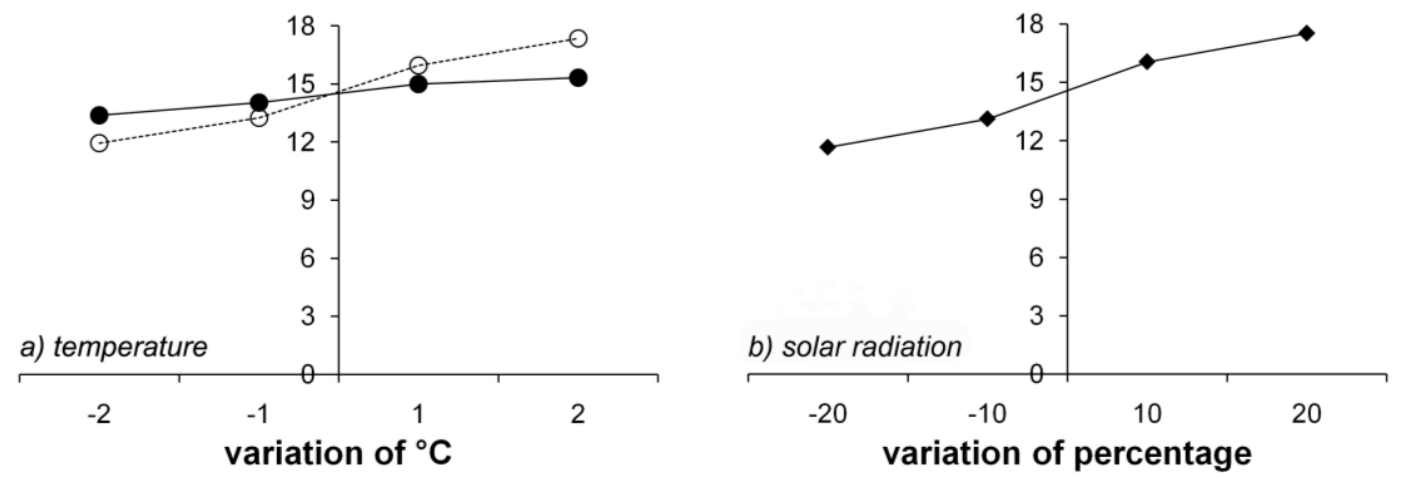

\section{Discussion}

This study determined the 3-PG model parameter values for a deciduous broadleaf forest dominated by B. platyphylla. The original parameter values were proposed for Eucalyptus forest plantations in Australia [10]. Some authors have directly applied these available parameters to other tree species or indirectly applied tuning methods $[12,13,16,24]$. The parameter values determined in this study corresponded to mature forest, focusing on biomass production. Data from young forests were not available, so we could not investigate forest growth rate or complete an age-series analysis with the 3-PG model.

An allometric analysis was performed to parameterize biomass partitioning between $W_{S}$ and $W_{F}$. Our model results were in agreement with empirical data (Figure 6) after parameterization. Even though some default parameter values were used, doing so did not cause significant errors in the output [17]. pFS2 and pFS20 values were moderately different from previous studies [7,10,11]. Deciduous broadleaf forests have annual leaf cycles, and biomass is typically stored in stems and branches throughout the year. However, DBH growth is small due to the short growing season in cool-temperate forests [25,26]. Even though age-series data were not available, trees with different DBH were present, and were assumed to represent different tree ages; these trees were used to find the relationship between relative annual growth rate and above-ground biomass. The relative annual growth rate of estimated above-ground biomass had a trend similar to the observed one. Foliage biomass was highly responsive to leaf phenology (i.e., leaf growth, maturation, senescence, and leaf fall). Litterfall was calculated as a constant fraction of foliage biomass corresponding to leaf growing conditions.

In parameterization, growth modifiers are the main factors affecting GPP calculations [8]. Among the growth modifiers, the temperature modifier had the most effect on $\alpha_{C x}$. Because our study site was constrained by temperature, the 3-PG model was run so that GPP $=0$ when the temperature was lower than $T_{n}$ or higher than $T_{x}$. The temperature at both study sites never reached $T_{x}$ because it is a cool-temperate area; thus, $T_{x}$ had no effect on GPP calculations. However, the temperature in the 
winter was always lower than $T_{n}$, and this affected the number of frost days. Thus, the 3-PG model generated GPP values of 0 at Hitsujigaoka and Takayama during winter. GPP is a function of environmental factors and the interception of radiation for photosynthetic processes. Thus, solar radiation (Figure 9b) increased GPP in relation to leaf area. Soil water may be limited at other forest sites, as found in Eucalyptus forest plantations by Esprey et al. [27]. In that case, increased precipitation resulted in increased stand volume, which is relevant to stem biomass. However, our study sites were not limited by water stress because they were located in an Asian monsoon climate region with high precipitation [28]. Additionally, snow melt increases the amount of soil water in the summer. Therefore, precipitation had no effect on GPP.

Biomass production, especially $W s$ and GPP, was controlled by $\alpha_{C x}$ and $T_{\text {opt }}$ (Figure 8). $\alpha_{C x}$ can be highly sensitive, relative to other input parameters [16,27], and directly affects the calculation of GPP. Changes in $\alpha_{C x}$ result in significant differences in GPP. $T_{\text {opt }}$ had an inverse relationship with GPP, such that lower temperatures resulted in higher GPP. $T_{n}$ influenced GPP in the deciduous broadleaf forest examined here, but had no effect in previous studies [27,29]. The large differences in $a_{s}$ and $n_{s}$ had strong influences on $W_{F}$. Almeida et al. [11] also reported the effect of $a_{s}$ and $n_{s}$ on $W_{F}$ for $E$. grandis. Increased $n_{s}$ resulted in increased $W_{F}$ partitioning. However, it is important to note that the various output types had different sensitivity to changes in each parameter.

Even though the growing cycle of deciduous broadleaf forests differs from that of other forest types, such as tropical forest, the set of parameter values indicates that it is not necessary to use a different ratio. Since the parameter values were determined over the entire growing season and there were no leaves in the winter, 3-PG will calculate a GPP of 0 if LAI equals 0 . Therefore, there were not increases or losses of biomass during winter. One caveat regarding this study is that root biomass was not included because root data were unavailable at the study site.

The 3-PG model can be applied to estimate biomass production for the deciduous broadleaf tree B. platyphylla. However, long-term empirical data are needed for better understanding parameterization, validating models, and making further improvements in the performance of the 3-PG model.

\section{Conclusions}

After parameterization, the 3-PG model is applicable to mature, non-water limited deciduous broadleaf forests. The main parameters affecting biomass production are assigned appropriate values from a set of standard parameter values. Some parameters are determined based on empirical data such as the allometric relationships between stem biomass and stem diameter, or between foliage biomass and stem diameter, as well as growth modifiers. Parameters for which empirical data are not available are determined by fitting the output to the observed data. The parameterization in this study emphasized biomass production. Default values were used for parameters that are not involved in biomass production.

\section{Acknowledgements}

We would like to sincerely thank to National Institute of Advanced Industrial Science and Technology (AIST), Gifu University and Shin Nagai for providing us the flux tower data at Takayama, as well as Kenlo Nishida Nasahara for LAI data. Furthermore, we would like to give special thank 
Hokkaido Research Center, Forestry and Forest Products Research Institute (FFPRI) especially Hajime Utsugi for the data at Hitsujigaoka. We deeply thank to Takahiro Endo for his valuable comments and all kind supports.

\section{References}

1. Farquhar, G.D.; Von Caemmerer, S.; Berry, J.A. A biochemical model of photosynthetic $\mathrm{CO}_{2}$ assimilation in leaves of C3 species. Planta 1980, 149, 78-90.

2. Landsberg, J.J.; Gower, S. Application of Physiological Ecology to Forest Management; Academic Press: San Diego, CA, USA, 1997.

3. Waring, R.H. A process-based model analysis of environmental limitations on growth of Sitka spruce plantations in Great Britain. Forestry 2000, 73, 65-79.

4. Coops, N.C.; Waring, R.H.; Landsberg, J.J. Assessing forest productivity in Australia and New Zealand using a physiologically-based model driven with averaged monthly weather data and satellite derived estimates of canopy photosynthetic capacity. Forest. Ecol. Manage. 1998, 104, 113-127.

5. Landsberg, J.J.; Johnsen, K.H.; Albaugh, T.J.; Allen, L.; McKeand, S.E. Applying 3-PG, a simple process-based model designed to produce practical results, to data from loblolly pine experiments. Forest. Sci. 2000, 47, 43-51.

6. Law, B.E.; Waring, R.H.; Anthoni, P.M.; Aber, J.D. Measurements of gross and net ecosystem productivity and water vapour exchange of a Pinus ponderosa ecosystem, and an evaluation of two generalized models. Glob. Change Biol. 2000, 6, 155-168.

7. Dye, P.J. Modelling growth and water use in four Pinus patula stands with the 3-PG model. South Afr. Forest. J. 2001, 191, 53-63.

8. Landsberg, J.J.; Waring, R.H. A generalised model of forest productivity using simplified concepts of radiation-use efficiency, carbon balance and partitioning. Forest. Ecol. Manage. 1997, 95, 209-228.

9. Landsberg, J.J.; Waring R.H.; Coops, N.C. Performance of the forest productivity model 3-PG applied to a wide range of forest types. Forest. Ecol. Manage. 2003, 172, 199-214.

10. Sands, P.J.; Landbergs, J.J. Parameterisation of 3-PG for plantation grown Eucalyptus globules. Forest. Ecol. Manage. 2002, 163, 273-292.

11. Almeida, A.C.; Landsberg, J.J.; Sands, P.J. Parameterisation of 3-PG model for fast-growing Eucalyptus grandis plantations. Forest. Ecol. Manage. 2004, 193, 179-195.

12. Dye, P.J.; Jacobs, S.; Drew, D. Verification of 3-PG growth and water-use predictions in twelve Eucalyptus plantation stands in Zululand, South Africa. Forest. Ecol. Manage. 2004, 193, 197-218.

13. Coops, N.C.; Waring, R.H. Estimating forest productivity in the eastern Siskiyou Mountains of southwest Oregon using a satellite driven process model, 3-PGS. Can. J. Forest. Res. 2001, 31, 143-154.

14. Coops, N.C.; Waring, R.H. The use of multiscale remote sensing imagery to derive regional estimates of forest growth capacity using 3-PGS. Remote Sens. Environ. 2001, 75, 324-334. 
15. Whitehead, D.; Hall, G.M.J.; Walcroft, A.S.; Brown, K.J.; Landsberg, J.J.; Tissue, D.T.; Turnbull, M.H.; Griffin, K.L.; Schuster, W.S.F.; Carswell, F.E.; Trotter, C.M.; James, I.L.; Norton, D.A. Analysis of the growth of rimu (Dacrydium cupressinum) in South Westland, New Zealand, using process-based simulation models. Int. J. Biometeorol. 2002, 46, 66-75.

16. Almeida, A.C.; Landsberg, J.J.; Sands, P.J.; Ambrogi, M.S.; Fonseca, S.; Barddal, S.M.; Bertolucci, F.L. Needs and opportunities for using a process-based productivity model as a practical tool in fast growing Eucalyptus plantation. Forest. Ecol. Manage. 2004, 193, 167-177.

17. Arneth, A.; Kelliher, F.M.; McSeveny, T.M.; Byers, J.N. Net ecosystem productivity, net primary productivity and ecosystem carbon sequestration in a Pinus radiata plantation subject to soil water deficit. Tree Physiol. 1998, 18, 785-793.

18. Waring, R.H.; Landsberg, J.J.; Williams, M. Net primary production of forests: A constant fraction of gross primary production. Tree Physiol. 1998, 18, 129-134.

19. Ohtsuka, T.; Akiyama, T.; Hashimoto, Y.; Inatomi, M.; Sakai, T.; Jia, S.; Mo, W.; Tsuda, S.; Koizumi, H. Biometric based estimates of net primary production (NPP) in a cool-temperate deciduous forest stand beneath a flux tower. Agr. Forest. Meteorol. 2005, 143, 27-38.

20. Site Information. Asiaflux: Tsukuba, Japan, 2009; Available online: http://www.asiaflux.net/ sf_fsreast.html (accessed on 9 May 2009).

21. Saigusa, N.; Yamamoto, S.; Murayama, S.; Kondo, H.; Nishimura, N. Gross primary production and net ecosystem exchange of a cool-temperate deciduous forest estimated by the eddy covariance method. Agr. Forest. Meteorol. 2002, 112, 203-215.

22. Nasahara, K.N.; Muraoka, H.; Nagai, S.; Mikami, H. Vertical integration of leaf area index in a Japanese deciduous broad-leaved forest. Agr. Forest. Meteorol. 2008, 148, 1136-1146.

23. Nakai, Y.; Kitamura, K.; Suzuki, S.; Abe, S. Year-long carbon dioxide exchange above a broadleaf deciduous forest in Sapporo, Northern Japan. Tellus 2003, 55B, 305-312.

24. Nightingale, J.M.; Hill, M.J.; Phinn, S.R.; Davies, I.D.; Held, A.A.; Erskine, P.D. Use of 3-PG and 3-PGS to simulate forest growth dynamics of Australian tropical rainforest: I. Parameterisation and calibration for old-growth, regenerating and plantation forests. Forest. Ecol. Manage. 2008, 254, 122-133.

25. Maruyama, K.; Fukumoto, Y.; Kamitani, T. The daily radial fluctuation of trunks of some deciduous broad-leaved tree and its controlling factors. J. Jpn. Forest. Soc. 1985, 67, 148-152 (in Japanese).

26. Komiyama, A.; Inoue, S.; Ishikawa, T. Characteristics of the seasonal diameter growth of twenty-five species of deciduous broad-leaved trees. J. Jpn. Forest. Soc. 1987, 69, 379-385 (in Japanese).

27. Esprey, L.J.; Sands, P.J.; Smith, C.W. Understanding 3-PG using a sensitivity analysis. Forest. Ecol. Manage. 2004, 193, 235-250.

28. Ito, A.; Saigusa, N.; Murayama, S.; Yamamoto, S. Modeling of gross and net carbon dioxide exchange over a cool-temperate deciduous broad-leaved forest in Japan: Analysis of seasonal and interannual change. Agr. Forest. Meteorol. 2005, 134, 122-134. 
29. Battaglia, M.; Sands, P.J. Application of sensitivity analysis to model of Eucalyptus globules plantation productivity. Ecol. Model. 1998, 111, 237-259.

(C) 2011 by the authors; licensee MDPI, Basel, Switzerland. This article is an open access article distributed under the terms and conditions of the Creative Commons Attribution license (http://creativecommons.org/licenses/by/3.0/). 